\title{
Control of Tumor Progression by Extracellular Matrix Molecule Fragments, the Matrikines
}

\author{
Jean Claude Monboisse ${ }^{1,2 *}$, Jean Baptiste Oudart ${ }^{1,2}$, Stéphane Brezillon ${ }^{1}$, Bertrand Brassart ${ }^{1}$, Laurent Ramont ${ }^{1,2}$, François Xavier Maquart ${ }^{1,2}$ \\ and Sylvie Brassart-Pasco ${ }^{1}$
}

${ }^{1}$ FRE CNRS/URCA 3481, Université Reims Champagne Ardenne, UFR Médecine, 51 Rue Cognacq Jay, 51095, REIMS Cedex, France

${ }^{2}$ Laboratoire Central de Biochimie, CHU Reims, 51092 Reims, France

\begin{abstract}
Tumor microenvironment is a complex system composed of a largely altered Extracellular Matrix (ECM) with different cell types that determine tumor progression. Upon the influence of hypoxia, tumor cells secrete cytokines that activate stromal cells to produce proteases and angiogenic factors. The proteases degrade the stromal ECM and participate in the release of various ECM fragments, named matrikines or matricryptins, capable to control tumor invasion and metastasis dissemination. The putative targets of the matrikine action are the proliferation and invasive properties of tumor or inflammatory cells, and the angiogenic and lymphangiogenic responses. In the present review, we will describe pro-tumorigenic effects triggered by soluble elastin or Elastin-Derived Peptides (EDPs), as well as the anti-tumorigenic or anti-angiogenic activities the matrikines derived from basement membrane associated collagens and several proteoglycans such as perlecan or lumican. Matrikines constitute a new family of potent anticancer agents that could be used under various therapeutic strategies: i) induction of their overexpression by cancer cells or by the host, ii) use of recombinant proteins or synthetic peptides or structural analogs designed from the structure of the active sequences. Matrikines could be used in combination with conventional chemotherapy or radiotherapy to limit tumor progression.
\end{abstract}

Keywords: Tumor microenvironment; Extracellular matrix; Matricryptins; Control of tumor progression

\section{Introduction}

Tumor progression is a multigenic and multistep process that involves many interactions between tumor cells and the surrounding microenvironnement. The latter consists of a highly modified extracellular matrix and cells (fibroblasts, endothelial cells, immune cells, etc.). Tumor microenvironment appears to be critical for the future of cell signaling cascades. Tumor cells and stromal cells exert cross-talks influencing behavior of each other. The cellular cross-talks trigger cell activation and the formation of a microenvironment that determines the proliferation of tumor cells, their invasive properties and therefore their metastatic potential [1]. These interactions also lead the tumor cells to secrete proteases that degrade ECM macromolecules and release ECM-stored growth factors. In particular, fibroblasts can be activated by growth factors such as TGF $\beta$, chemokines as SDF1 or even proteases (MMP-2, -9 or MMP-14), that degrade ECM macromolecules, triggering an increased cell proliferation and ECM protein synthesis, such as type I collagen, tenascin $\mathrm{C}$ or fibronectin. These activated fibroblasts share phenotypic morphology with myofibroblasts, mainly the expression of a smooth muscle actin, and are named CAF (cancer associated fibroblasts) [2,3]

Fibroblasts activated by the tumor microenvironment are largely responsible for tumor-associated changes in ECM. These changes include upregulated ECM synthesis, posttranslational modifications of ECM and extensive remodeling of ECM macromolecules by MMPs. The altered ECM then influences tumor progression by architectural and signaling interactions [4]. Using mass spectrometric analysis, it was demonstrated in cancer xenograft models that both tumor cells and stromal cells contribute to the secretion of proteins making up the tumor ECM. Several proteins, such as periostin, not secreted in normal skin, become expressed by tumor cells and the stroma during tumor progression and metastasis [5]. In addition, the proteins secreted by the tumor cells may vary with their metastatic potential. The matrix components secreted by stromal cells also change in response to the metastatic potential of the tumor cells, indicating significant cross-talk between tumor and stromal cells [5]. The interstitial matrix is a major ECM, comprising fibrillar collagens, fibronectin and proteoglycans. It provides a structural bed to the cells and binds growth factors or cytokines. The synthesis and remodeling of the fibrillar type I collagen increases in tumors and is required for angiogenesis. The architecture of type I collagen also changes, with a progressive modification of fibers orientation, promoting cell migration along the collagen fibers, or by enhancing integrin signaling [4].

In addition to the microenvironment architectural structure changes, tumor angiogenesis constitutes another important mechanism which plays a crucial role in tumor progression. When the tumor reaches a critical size of a few millimeters in diameter, hypoxia, acidosis and nutrient deprivation lead to an "angiogenic switch" characterized by alteration in gene, microRNA [6], and growth factor expression and secretion. Hypoxia is the main endogenous stimulus of tumor angiogenesis, and VEGF is one of its target. Endothelial cells are activated by angiogenic growth factors, in particular VEGF. They acquire a proliferative capacity and synthesize proteases that degrade the pre-existing basement membrane and allow them to migrate within the tumor.

*Corresponding authors: Jean Claude Monboisse ,FRE CNRS/URCA 3481, Université Reims Champagne Ardenne, UFR Médecine, 51 Rue Cognacq Jay, 51095, REIMS Cedex, France, Tel:+33326913534;Fax :+ 33326918055; E-mail: jc.monboisse@univ-reims.fr

Received July 16, 2013; Accepted August 21, 2013; Published August 26, 2013

Citation: Monboisse JC, Oudart JB, Brezillon S, Brassart B, Ramont L, et al (2013) Control of Tumor Progression by Extracellular Matrix Molecule Fragments, the Matrikines. J Carcinogene Mutagene 4: 148. doi:10.4172/2157-2518.1000148

Copyright: $\odot 2013$ Monboisse JC, et al. This is an open-access article distributed under the terms of the Creative Commons Attribution License, which permits unrestricted use, distribution, and reproduction in any medium, provided the original author and source are credited. 
In tumor progression, the cell-matrix interactions can be controlled by the ECM macromolecules either by intact ECM molecules or through some of their constitutive domains, released by limited proteolysis or by exposing cryptic sites. These domains, named matrikines, are protein domains exerting a biological activity [7]. The term of matricryptin was also proposed when the protein domain has a biological activity not carried by the native protein and unmasked by proteolysis [8]. Various matrikines have been described in the literature as endogenous inhibitors of angiogenesis [9]. Some of them derive from elastin or laminins and exert pro-angiogenic or pro-tumor activities, whereas others exert both anti-angiogenic and anti-tumorigenic properties. In the present review, we will describe pro-tumorigenic effects triggered by soluble elastin or Elastin Derived Peptides (EDPs), as well as the anti-tumorigenic or anti-angiogenic activities the matrikines derived from basement membrane associated collagens and several proteoglycans such as perlecan or lumican.

\section{Pro-Tumor Matrikines}

\section{Elastin}

Elastin, an insoluble ECM macromolecule matured from tropoelastin, constitutes the main amorphous component of elastic fibers, responsible for the tissue elastic properties [10]. Elastin turnover is almost absent in normal physiological conditions explaining the half-life of elastin of about 74 years [11]. However, large amount of elastin peptides are produced during several pathological and physiopathological processes [12-14]. The elastokine word has been proposed to define bioactive peptides derived from elastin by proteolytic cleavage [15]. MMPs, such as MMP-2, MMP-9, MMP-7 and the macrophage metalloelastase MMP-12 are efficient elastases expressed in diverse pathologies associated to strong elastin degradation, as well as leukocyte elastase, cathepsin G and L [16-18]. K-elastin corresponds to a heterogeneous mixture of EDPs obtained by potassic solubilisation of elastin [19]. These peptides exert a variety of bioactivities in normal and tumor cells. Some of them contain the GXXPG motif that enables them to bind on cell surface to the elastin binding protein but also to $\alpha \mathrm{V} \beta 3$ integrin and galectin-3 [20-22]. All the EDPs in which the central residues are not glycine, adopt a canonical (or very close to) type VIII $\beta$-turn structure on the GXXP sequence, crucial for biological activity [23]. Any residue located before the GXXP motif (XGXXP) increases the $\beta$-turn stabilization, whereas the residue located after GXXP (GXXPX) has no significant structural effect [24].

Tropoelastin and EDPs promote proliferation of human tumor cells as described on astrocytoma cell lines [25]. EDP treatment increases invasive properties by upregulating the expression of MMP1 and MMP-2 in human fibrosarcoma HT-1080 cells; the effect was reproduced by the synthetic VGVAPG peptide [23,26,27]. When bound to S-Gal elastin receptor, EDPs enhance melanoma cell invasion in a three-dimensional type I collagen matrix by upregulating MMP-2 activation [28]. They also induce NF- $\kappa B$ activation, leading to IL- $1 \beta$ upregulation in invasive melanoma cells [29]. In vivo, the increased levels of EDPs facilitate the invasion of melanoma cells by exerting chemotactic effects [21]. The increased migration of tumor cells may be explained by an increase in the expression of CXCR- 4 and CXCL-12 chemokines and of the elastin-degrading MMP-2 and MMP-3 or an increase in the expression of different adhesion molecules. K-elastin and the synthetic peptide (VGVAPG), increase the invasiveness of malignant glioma cells by upregulating MMP-2 expression and by inducing the synthesis of MMP-12 [30]. K-elastin peptides also increased the invasiveness of invasive lung tumor cells without affecting noninvasive cells and triggered a secretion of pro-MMP-2 and urokinase plasminogen activator (uPA) with an increase in proMMP2 activation [31]. All these effects were not inhibited by two Elastin Receptor Complex antagonists (lactose and the peptide V14) or by $\alpha \mathrm{V} \beta 3$ integrin- and galectin-3 blocking antibodies. Synthetic peptides such as VGVAPG, used to specifically target EBP and Gal-3, and GRKRK, used to target $\alpha \mathrm{V} \beta 3$ integrin, failed to reproduce $\kappa$-elastin effects whereas the nonapeptides AGVPGLGVG and AGVPGFGAG, used to target a yet unknown, lactose-insensitive nonapeptide receptor, partially mimicked them [31].

\section{Basement Membrane Collagen Derived Anti-Tumor Matrikines}

Basement membranes are highly specialized ECM that represent a frontier between the epithelium and the underlying matrix. They consist of type IV collagen associated with collagens XV, XVIII and XIX, structural glycoproteins (laminins, nidogen/entactin,) and proteoglycans, as perlecan [32]. They not only provide a mechanical support for cells, but they may also serve as a reservoir of growth factors and cytokines. After release by proteases such as MMPs, these growth factors and cytokines may control various cell functions. By interaction with the cells, they regulate biological activities such as migration, proliferation or cell differentiation [33].

\section{Collagen IV}

Collagen IV, the major component of basement membranes, is formed by the association of three $\alpha(\mathrm{IV})$ chains among six possibles, $\alpha 1(I V)$ to $\alpha 6(I V)$, each encoded by a specific gene [34]. While a1(IV) and $\alpha 2$ (IV) chains are ubiquitous, the other $\alpha(I V)$ chains, in smaller proportion, are expressed in specialized basement membranes [35]. Various matrikines or matricryptins derive from the different $\mathrm{NCl}$ C-terminal domains of the different $\alpha$ (IV) collagen chains.

Arresten, the NClal(IV) domain, exert anti-angiogenic activity by binding to $\alpha 1 \beta 1$ integrin and inducing an intracellular transduction signal leading to the inhibition of HIF-1 $\alpha$ factor $[36,37]$. The inhibition causes a tumor growth decrease in various cancer and liver metastasis models $[38,39]$.

Canstatin, the NC1a2(IV) domain, is an endogenous inhibitor of angiogenesis. In vitro, it inhibits the proliferation and migration of endothelial cells and their protein synthesis $[40,41]$. The N-terminal part (residues 1-89) of canstatin is responsible for cell apoptosis induction while the C-terminal part (residues 157-227) specifically inhibits endothelial cell proliferation $[42,43]$. Canstatin also induces a decrease in angiopoietin-1 expression in endothelial cells and lymphatic endothelial cells under hypoxic conditions [44]. The induction of apoptosis involves two signaling pathways, a first one depending on a Fas/Fas ligand pathway with activation of caspases 8 and 3 , and a second one initiated by the binding of canstatin to $\alpha \mathrm{V} \beta 5$ integrin $[45,46]$. Canstatin inhibits tumor growth in various in vivo cancer models when overexpressed by tumor cells $[40,44,45]$.

Tumstatin, the NC1a3(IV) domain, exerts both anti-angiogenic and anti-tumor activities by two distinct sequences [47]. The sequence 54-132 named Tum-5, is responsible for the anti-angiogenic activity by induction of apoptosis in endothelial cells. Its binding to the av $\beta 3$ integrin, independently of the RGD sequence induces a transduction pathway similar to that induced by canstatin, with down-regulation of the mTOR pathway and protein synthesis [48]. In the C-terminal part of tumstatin, a second sequence corresponding to residues 185-203, has a strong anti-tumor activity, demonstrated in murine and human melanoma models, either by using synthetic peptides reproducing 
the sequence or by inducing its overexpression by cancer cells [4951]. This sequence also inhibits the proteolytic cascades of tumor progression, MMPs and plasminogen activation. This sequence binds to $\alpha v \beta 3$ integrin, independently of the RGD sequence, and triggers an intracellular transduction pathway involving the early phosphorylation of FAK and PI3 kinase [52].

Tumstatin is produced in vivo by cleavage of collagen IV by MMP9, as demonstrated by using MMP-9 knockout mice. By ELISA, the serum concentration of circulating tumstatin was determined in mice (300-360 ng/mL) [53]. In our laboratory, we found mouse serum tumstatin concentrations of $600 \mathrm{ng} / \mathrm{mL}$ [54]. The concentration of circulating tumstatin was also determined in human (10 to $150 \mathrm{ng} /$ $\mathrm{mL}$ ), confirming its in vivo production and physiological interest in the control of tumor growth [55].

An anti-angiogenic activity has been demonstrated in the chicken chorioallantoic membrane model for the recombinant NC1 domains derived from the different $\alpha(I V)$ collagen chains, but no activity was found for the NC1a4(IV) domain [56]. However, its overexpression induced in human melanoma cells by stable transfection causes an anti-proliferative effect on these cells and a significant inhibition of their invasive properties. This decrease in invasive properties is due, at least in part, to a reduction of the amount of active MMP-14 at the migration front, inducing a non-migratory cell phenotype. In a xenograft model of human melanoma in mice, the NC1a4(IV) domain, named tetrastatin, induces a decrease of more than $80 \%$ in tumor growth [57].

Only few studies have been devoted to the NC1 a5(IV) domain, although its strong anti-angiogenic activity was demonstrated in the chicken chorioallantoic membrane model [56]. Peptide sequences of this domain, named pentastatin 1,2 and 3 respectively, inhibit in vitro proliferation and migration of endothelial cells [58]. Pentastatin 1, corresponding to residues 1516-1535 of the a5(IV) chain has a strong anti-angiogenic activity in an in vivo angiogenesis model in mice and reduces tumor growth in a xenograft model of non-small cell lung cancer [59].

Hexastatin, the a6(IV) NC1 domain, inhibits endothelial cell proliferation, adhesion and migration as well as neovascularization in matrigel plugs in normal C57Bl/6 mice. Similarly, it reduces tumor growth in Lewis lung carcinoma and in Rip1Tag2 transgenic mice which develop spontaneous pancreatic carcinoma [60].

Intracellular transduction pathways triggered by collagen IVderived matrikines essentially result in the inhibition of FAK/PI3K/ Akt pathway, preventing the release of the translation initiation factor eIF4E and leading to the inhibition of protein synthesis through the mTOR pathway [46,48]. Tumstatin also inhibits NF-kB signaling resulting in inhibition of COX-2 mediated signaling [46].

The destruction of the basement membrane is the first step in epithelial cancer invasion and metastasis. Tumor sections from patients with lung carcinoma show an expression of tumstatin around some cancer clusters [61]. In 34 patients with lung carcinoma, a strong expression of tumstatin is associated with a lesser degree of tumor vascularization [62]. In patients with non-small lung cancer, tumor tumstatin-mRNA expression was significantly related to tumor pathologic stage and patients with low tumstatin-mRNA expression had poorer overall survival and disease-free survival than those with high expression [63]. As well, the loss of $\alpha 5$ (IV) and a6(IV) chains from the epithelial basement membrane at the early stage of cancer invasion has been reported in several types of cancer $[64,65]$. In hepatic bile duct carcinoma, the absence of $\alpha 2$ (IV) and $\alpha 6$ (IV) chains corresponds to a significantly poorer prognosis [66]. Nevertheless, in gastric carcinomas, an overexpression of COL4A3 appears to be negatively associated with a favorable prognosis and an aberrant COL4A 3 expression might play an important role in the pathogenesis and subsequent progression of gastric carcinoma [67].

\section{Collagens XV and XVIII}

These two collagens constitute the multiplexin family. Collagen $\mathrm{XV}$ is mainly located in the basal neuronal, mesenchymal, vascular membranes, and some epithelial basement membranes. Proteolysis of the C-terminal NC1 domain gives rise to a matrikine, restin, which exerts an anti-tumor effect based on its anti-angiogenic properties [68]

Collagen XVIII, initially described as a heparan sulfate proteoglycan, presents a high structural homology with collagen $\mathrm{XV}$ [69]. The cleavage of its C-terminal NC1 domain by different MMPs (MMP-2, -7, -9, -14) or other proteases gives rise to a $20 \mathrm{kDa}$ matrikine, endostatin [70]. Anti-tumor and anti-angiogenic activities of endostatin have been widely described in literature and will not be described here [71,72].

Collagen XVIII also contains cryptic polypeptide modules, such as an N-terminal variant containing a frizzled module (FCZ 18), sharing a structural identity with the extracellular cysteine-rich domain of the frizzled receptors. This domain inhibits in vivo cell proliferation and tumor growth in mice through the $\mathrm{Wnt} / \beta$-catenin signaling pathway $[73,74]$.

\section{Collagen XIX}

Collagen XIX is a minor FACIT collagen associated with type IV and XVIII collagens in basement membranes. It is a homotrimer of three $\alpha 1$ (XIX) chains [75]. Type XIX collagen expression is ubiquitous during embryogenesis, but its expression in adult is restricted to specialized basement membranes like vascular, neuronal, mesenchymal or epithelial tissues [76]. It seems to play an important role in muscle differentiation [77] and in the formation of hippocampal synapses [78].

The short NC1 (XIX) C-terminal domain is composed of 19 residues and inhibits the migration and invasion capacities of melanoma cells in vitro without affecting their proliferation [79]. It exerts also a strong inhibition of in vivo tumor growth in a murine melanoma model with a decrease in tumor vascularization. NC1(XIX) inhibited in vitro pseudotube formation in matrigel by human microvascular endothelial cells. This effect was accompanied by an intense inhibition of MMP-14 and VEGF expression [80].

Collagen XIX disappears from basement membrane during breast cancer progression at invasive stages [81].

A competitive ELISA assay was developed to determine NC1 (XIX) concentration in the sera of patients. NC1(XIX) was easily detectable in the sera [82].

\section{Proteoglycans and Proteoglycan-Derived Matrikines}

Initially thought to act exclusively as structural components, proteoglycans are now recognized as key players in cell functions such as proliferation, differentiation, survival, adhesion, migration, or inflammatory response, due in part to their ability to sequester cytokines and growth factors. The expression of proteoglycans is largely altered in various cancers [83-85]. Proteoglycan-derived peptides such as endorepellin, a perlecan fragment, lumcorin derived from lumican, 
and decorin-derived peptides were found to play a role in the control of tumor progression, angiogenesis, and metastasis by exerting antitumor properties [86-91].

\section{Endorepellin, a perlecan-derived peptide}

Perlecan is a large proteoglycan, present in almost all basement membranes where it interacts with laminin-1 and collagen IV, as well as with $\beta 1$-integrins [92]. The regulatory role of perlecan in tumor progression was demonstrated in human colon carcinoma xenograft and melanoma allograft models: the suppression of perlecan expression caused substantial inhibition of tumor growth and angiogenesis [84]. Perlecan can be pro-angiogenic by direct interaction with VEGFR2 pathway. The role of perlecan in regulating the angiogenic switch results from its opposing terminal angiogenic activities [93]. The N-terminus, which includes three heparan sulfate chains, harbours a number of angiogenic growth factors including FGFs, progranulin and VEGFA, in close proximity to their functional receptors [94-97]. In contrast, the limited proteolysis of its C-terminus by BMP-1 or cathepsin L liberates a bioactive angiostatic fragment named endorepellin to designate its intrinsic repulsive activity against endothelial cells $[98,99]$. Its angiostatic activity exists through binding to $\alpha 2 \beta 1$ integrin that induces a signaling cascade leading to actin cytoskeleton collapse and activation of the tyrosine phosphatase SHP-1, which in turn dephosphorylates several tyrosine kinase receptors, including VEGFR2 [100,101].

\section{Lumcorin, a lumican-derived peptide}

Lumican is a member of the Small Leucin Rich Proteoglycan (SLRP) family able to regulate cell proliferation, adhesion, migration and tumor invasion in melanoma [86,102-106]. Its core protein increases melanoma cell adhesion [107] while, in its glycosylated form, lumican inhibits melanoma cell migration and invasion [102-104]. It inhibits anchorage-independent cell proliferation, migration, or invasion and increases melanoma cell apoptosis. In an in vivo mouse melanoma model with lumican-overexpressing B16F1 melanoma cells, tumor progression is significantly inhibited [102]. Through binding to $\alpha 2 \beta 1$ integrin, it inhibits melanoma cell migration via alteration of actin network and focal adhesion complexes [104, 106, 108]. Lumican also exerts angiostatic properties by inhibiting endothelial cell invasion, angiogenic sprouting and vessel formation in mice [105,109-112]. This inhibitory effect on endothelial cell migration is associated with the downregulation of the expression and activity of MMP-9 and MMP14 [111]. In our laboratory, within the Leucin Rich Repeat 9 (LLR9), we identified a 17 amino acid sequence inhibiting in vitro melanoma cell migration and reproducing the anti-migratory effect of lumican. This sequence was named lumcorin (fragment of lumican core protein) [113].

Lumican acts as an endogenous inhibitor of TGF $\beta 2$ pathway, resulting in modulation of downstream effectors, such as pSmad 2 or $\beta 1$ integrin and phosphorylation of p125FAK in osteosarcoma cells [114]

Lumican expression in pancreatic cancer correlates with an advanced stage and retroperitoneal and duodenal invasion [115]. The expression of lumican protein did not correlate with prognostic factors in breast carcinoma [116], but reduced lumican protein expression is associated with a poor outcome in breast cancer [117].

\section{Decorin-derived peptides}

Decorin, another member of the SLRP family, is involved in tumor progression, angiogenesis and metastasis [87,88]. Decorin inhibits tumor cell growth, migration, angiogenesis, endothelial cell proliferation and motility and alters endocytosis $[88,118,119]$. It acts as a tumor suppressor by interacting with EGF Receptor (EGFR), ErbB, c-Met, Insulin-IGF Receptor (IGFR), TGF $\beta$ Receptor (TGF $\beta R$ ), and $\alpha 2 \beta 1$ integrin respectively. This induces the p $21^{\text {WAF-1 }}$ inhibitor of cell cycle progression, proteasome degradation, activation of PI3K/ Akt/mTOR and PI3K/Smad signalling [88]. Decorin peptides derived from its LRR5 present anti-angiogenic properties [91]. Among them, a LRR5-derived 26 amino acid peptide and its 13-mer C-terminal part decreases VEGF-stimulated migration of endothelial cells by inhibiting VEGF-stimulated endothelial nitric oxide synthase activation and NO release [120].

\section{Matrikine-Based Therapeutic Strategies}

Numerous preclinical trials using matrikines to limit tumor progression have been conducted in various experimental cancer models in mice. They used different strategies:in vivo matrikine overexpression using viral constructions or plasmid DNA electrotransfer -injections of recombinant proteins or synthetic peptides.

\section{Collagen IV derived matrikines}

The in vivo overexpression of canstatin in mice was obtained by an adenovirus encoding a fusion protein canstatin-human albumin or a fluorescent protein GFP-canstatin. The intratumoral injection of adenovirus causes a decrease in tumor growth [45,121]. Another construction, based on a plasmid containing the cDNA encoding the Tum-1 fragment of tumstatin and injected at regular intervals induces a significant decrease in tumor growth [122].

To avoid the side effects and the need for repeated injections, the use of DNA electrotransfer in muscle cells confirmed the anti-angiogenic and anti-tumor effects of canstatin in murine cancer models [123]. Similarly, in our laboratory, the in vivo overexpression of tumstatin or tetrastatin induced by DNA electrotransfer caused a strong decrease in tumor growth and increased mouse survival in a melanoma model [56].Collagen IV derived matrikines were produced in different cell systems. Their peri- or intra-tumor injections decreased tumor growth in experimental models of cancer in mice $[40,124,125]$.

Short peptide sequences are responsible for the anti-angiogenic and anti-tumor activities of tumstatin:

The 74-90 sequence, named T7 peptide, is responsible for the antiangiogenic activity [126]. A synthetic peptide reproducing a part of T7 peptide induces apoptosis in endothelial cells and inhibits tumor growth of gastric carcinoma in mice $[127,128]$.

The 185-203 sequence, is responsible for the anti-tumor activity [49]. Intravenous injection of the peptide inhibits tumor growth of melanoma or gastric carcinoma in mice $[128,129]$. Within this 185 203 sequence, the biological activity is contained in the $7 \mathrm{~N}$-terminal amino acid sequence (CNYYSNS) [130,131]. By molecular dynamics simulation, we showed that they form a $\beta$-turn [130]. A YSNSG cyclopeptide, forming a constrained $\beta$-turn was designed. In a model of melanoma, its inhibitory effect was higher than that of the native linear peptide, due to an increased stability $[132,133]$.

Preclinical studies in mice performed by using a matrikine, eg canstatin or tumstatin in combination with conventional chemotherapy or radiotherapy showed a potentiating effect compared to each treatment used separately $[45,123,126,131,134,135]$. 
Citation: Monboisse JC, Oudart JB, Brezillon S, Brassart B, Ramont L, et al. (2013) Control of Tumor Progression by Extracellular Matrix Molecule Fragments, the Matrikines. J Carcinogene Mutagene 4: 148. doi:10.4172/2157-2518.1000148

\section{Proteoglycan derived matrikines}

Systemic delivery of recombinant endorepellin to mice bearing orthotopic squamous carcinoma xenografts or syngeneic lung carcinoma tumors, caused a marked reduction of tumor growth, tumor metabolism and angiogenesis [136].

In a syngeneic mouse melanoma model, tumor progression was significantly reduced in tumor obtained by subcutaneous injection of lumican overexpressing melanoma cells [102]. Lumican is expressed in various cancer tissues but both positive and negative correlations with tumor aggressiveness have been reported and are largely discussed in [86].

As described for collagen IV-derived matrikines, similar tools have been used to demonstrate the anticancer effects of decorin in various cancer animal models, including adenoviral-mediated decorin gene delivery or systemic administration of recombinant decorin. A tumor xenograft approach obtained by injection of decorin-expressing cells showed a large decrease in tumor growth with a reduced neovascularization [137]. Systemic recombinant decorin delivery or de novo-induced expression of decorin inhibited tumor progression in different animal cancer models and induced a downregulation of the endogenous expression of VEGF and FGF2 [138]. In addition, decorin largely prevented lung metastasis in breast or osteosarcoma models $[119,139]$. In experimental combined therapy strategies, decorin exerts opposite effects: it synergizes with carboplatin to inhibit ovarian cancer cell growth, while it antagonizes the effects of carboplatin and gemcitabine on pancreatic cancer cells [88].

In tumors, proteoglycans may serve as preferred targets of chemotherapeutic drugs in order to improve their potential and minimize side effects. For example, the binding of a quaternary ammonium on an alkylating agent allows a specific address of this molecule on tumor proteoglycans in a rat chondrosarcoma [140].

The elastin peptides, including the previously described exert protumor effects by increasing the activation of the proteolytic cascades involved in tumor progression. The determination of their receptors on cancer cell surface and the characterization of their spatial structures (presence of $\beta$ turn for example) will permit to design structural analogs capable to act as antagonists to block signal transduction pathways induced by EDPs and thus to limit their pro-tumor effects.

\section{Clinical trials}

Clinical trials have been conducted or are underway with endostatin, but they proved to be ineffective. Currently, several clinical trials are underway in China, with Endostar, derived from endostatin, alone or in combination with conventional chemotherapy in patients with non-small lung cancer cells or colorectal and gastric cancers [141].

\section{Conclusions}

In vitro and preclinical studies in mouse cancer models highlight the strong potential of matrikines for new anti-cancer agent development. Their ability to inhibit the proliferative and invasive properties of cancer cells and their anti-angiogenic activity are opening new opportunities to limit tumor progression. In addition, their endogenous origin contributes to a better tolerance, limiting side effects. The characterization of the active minimal sequences will allow to design structural analogs and improve their bioavailability and pharmacokinetic properties. The binding of these matrikines or their analogs on cell surface receptors such as av $\beta 3$ integrin, will also develop strategies to target specific cancer cells and activated endothelial cells, to directly address chemotherapeutic molecules on their target cells and to decrease the doses and side effects. Matrikines and derived molecules are a new family of potent anti-cancer agents for use in therapeutic strategies combined with conventional chemotherapy or radiation and open up real prospects against tumor progression.

\section{Acknowledgements}

This work was supported by grants from the Centre National de la Recherche Scientifique (FRE 3481), the University of Reims Champagne-Ardenne, the Région Champagne-Ardenne and FEDER (Contrat de Plan Etat-Région 2007-2013), and the Ligue contre le Cancer.

\section{References}

1. Weis SM, Cheresh DA (2011) Tumor angiogenesis: molecular pathways and therapeutic targets. Nat Med 17: 1359-1370.

2. Kalluri R, Zeisberg M (2006) Fibroblasts in cancer. Nat Rev Cancer 6: 392-401.

3. Shimoda M, Mellody KT, Orimo A (2010) Carcinoma-associated fibroblasts are a rate-limiting determinant for tumour progression. Semin Cell Dev Biol 21: $19-25$.

4. Egeblad M, Nakasone ES, Werb Z (2010) Tumors as organs: complex tissues that interface with the entire organism. Dev Cell 18: 884-901.

5. Naba A, Clauser KR, Hoersch S, Liu H, Carr SA, et al. (2012) The matrisome: in silico definition and in vivo characterization by proteomics of normal and tumor extracellular matrices. Mol Cell Proteomics 11: M111.

6. Heusschen R, van Gink M, Griffioen AW, Thijssen VL (2010) MicroRNAs in the tumor endothelium: novel controls on the angioregulatory switchboard. Biochim Biophys Acta 1805: 87-96.

7. Maquart FX, Siméon A, Pasco S, Monboisse JC (1999) Regulation of cell activity by the extracellular matrix: the concept of matrikines. J Soc Biol 193 423-428.

8. Davis GE, Bayless KJ, Davis MJ, Meininger GA (2000) Regulation of tissue injury responses by the exposure of matricryptic sites within extracellular matrix molecules. Am J Pathol 156: 1489-1498.

9. Nyberg P, Xie L, Kalluri R (2005) Endogenous inhibitors of angiogenesis Cancer Res 65: 3967-3979.

10. Mithieux SM, Weiss AS (2005) Elastin. Adv Protein Chem 70: 437-461.

11. Shapiro SD, Endicott SK, Province MA, Pierce JA, Campbell EJ (1991) Marked longevity of human lung parenchymal elastic fibers deduced from prevalence of D-aspartate and nuclear weapons-related radiocarbon. J Clin Invest 87: 18281834.

12. Hornebeck W, Emonard H, Monboisse JC, Bellon G (2002) Matrix-directed regulation of pericellular proteolysis and tumor progression. Semin Cancer Biol 12: $231-241$

13. Pardo A, Selman M (1999) Proteinase-antiproteinase imbalance in the pathogenesis of emphysema: the role of metalloproteinases in lung damage. Histol Histopathol 14: 227-233.

14. Fülöp T, Larbi A (2002) Putative role of $67 \mathrm{kDa}$ elastin-laminin receptor in tumor invasion. Semin Cancer Biol 12: 219-229.

15. Duca L, Floquet N, Alix AJ, Haye B, Debelle L (2004) Elastin as a matrikine. Crit Rev Oncol Hematol 49: 235-244.

16. Heinz A, Jung MC, Duca L, Sippl W, Taddese S, et al. (2010) Degradation of tropoelastin by matrix metalloproteinases--cleavage site specificities and release of matrikines. FEBS J 277: 1939-1956.

17. Lombard C, Arzel L, Bouchu D, Wallach J, Saulnier J (2006) Human leukocyte elastase hydrolysis of peptides derived from human elastin exon 24. Biochimie 88: 1915-1921.

18. Schmelzer CE, Jung MC, Wohlrab J, Neubert RH, Heinz A (2012) Does human leukocyte elastase degrade intact skin elastin? FEBS J 279: 4191-4200.

19. Robert L (2010) The Saga of kappa-elastin or the promotion of elastin degradation products from "garbage" to receptor agonists and pharmacologically active principles. Connect Tissue Res 51: 8-13.

20. Taddese S, Weiss AS, Jahreis G, Neubert RH, Schmelzer CE (2009) In vitro degradation of human tropoelastin by MMP-12 and the generation of matrikines from domain 24. Matrix Biol 28: 84-91. 
Citation: Monboisse JC, Oudart JB, Brezillon S, Brassart B, Ramont L, et al. (2013) Control of Tumor Progression by Extracellular Matrix Molecule Fragments, the Matrikines. J Carcinogene Mutagene 4: 148. doi:10.4172/2157-2518.1000148

21. Pocza P, Süli-Vargha H, Darvas Z, Falus A (2008) Locally generated VGVAPG and VAPG elastin-derived peptides amplify melanoma invasion via the galectin-3 receptor. Int J Cancer 122: 1972-1980.

22. Bax DV, Rodgers UR, Bilek MM, Weiss AS (2009) Cell adhesion to tropoelastin is mediated via the C-terminal GRKRK motif and integrin alphaVbeta3. J Biol Chem 284: 28616-28623.

23. Brassart B, Fuchs P, Huet E, Alix AJ, Wallach J, et al. (2001) Conformational dependence of collagenase (matrix metalloproteinase-1) up-regulation by elastin peptides in cultured fibroblasts. J Biol Chem 276: 5222-5227.

24. Moroy G, Alix AJ, Héry-Huynh S (2005) Structural characterization of human elastin derived peptides containing the GXXP sequence. Biopolymers 78: 206220.

25. Jung S, Rutka JT, Hinek A (1998) Tropoelastin and elastin degradation products promote proliferation of human astrocytoma cell lines. J Neuropathol Exp Neurol 57: 439-448.

26. Brassart B, Randoux A, Hornebeck W, Emonard H (1998) Regulation of matrix metalloproteinase-2 (gelatinase A, MMP-2), membrane-type matrix metalloproteinase-1 (MT1-MMP) and tissue inhibitor of metalloproteinases-2 (TIMP-2) expression by elastin-derived peptides in human HT-1080 fibrosarcoma cell line. Clin Exp Metastasis 16: 489-500.

27. Huet E, Brassart B, Cauchard JH, Debelle L, Birembaut $P$, et al. (2002) Cumulative influence of elastin peptides and plasminogen on matrix metalloproteinase activation and type I collagen invasion by HT-1080 fibrosarcoma cells. Clin Exp Metastasis 19: 107-117.

28. Ntayi C, Labrousse AL, Debret R, Birembaut P, Bellon G, et al. (2004) Elastinderived peptides upregulate matrix metalloproteinase-2-mediated melanoma cell invasion through elastin-binding protein. J Invest Dermatol 122: 256-265.

29. Debret R, Le Naour RR, Sallenave JM, Deshorgue A, Hornebeck WG, et al. (2006) Elastin fragments induce IL-1beta upregulation via NF-kappaB pathway in melanoma cells. J Invest Dermatol 126: 1860-1868.

30. Coquerel B, Poyer F, Torossian F, Dulong V, Bellon G, et al. (2009) Elastinderived peptides: matrikines critical for glioblastoma cell aggressiveness in a 3-D system. Glia 57: 1716-1726.

31. Toupance S, Brassart B, Rabenoelina F, Ghoneim C, Vallar L, et al. (2012) Elastin-derived peptides increase invasive capacities of lung cancer cells by post-transcriptional regulation of MMP-2 and uPA. Clin Exp Metastasis 29: 511 522.

32. Kalluri R (2003) Basement membranes: structure, assembly and role in tumour angiogenesis. Nat Rev Cancer 3: 422-433.

33. Kruegel J, Miosge N (2010) Basement membrane components are key players in specialized extracellular matrices. Cell Mol Life Sci 67: 2879-2895.

34. Ricard-Blum S (2011) The collagen family. Cold Spring Harb Perspect Biol 3 a004978.

35. LeBleu V, Sund M, Sugimoto H, Birrane G, Kanasaki K, et al. (2010) Identification of the NC1 domain of \{alpha\}3 chain as critical for \{alpha\}3\{alpha\}4\{alpha\}5 type IV collagen network assembly. J Biol Chem 285: 41874-41885.

36. Colorado PC, Torre A, Kamphaus G, Maeshima Y, Hopfer H, et al. (2000) Antiangiogenic cues from vascular basement membrane collagen. Cancer Res 60: 2520-2526.

37. Sudhakar A, Nyberg P, Keshamouni VG, Mannam AP, Li J, et al. (2005) Human alpha1 type IV collagen NC1 domain exhibits distinct antiangiogenic activity mediated by alpha1beta1 integrin. J Clin Invest 115: 2801-2810.

38. Long MY, Li HH, Xu JY, Lai DM, Weng ZH (2008) Inhibitory effects of transfection of arresten gene on liver metastasis from colorectal cancer in nude mice. Ai Zheng 27: 1039-1043.

39. Aikio M, Alahuhta I, Nurmenniemi S, Suojanen J, Palovuori R, et al. (2012) Arresten, a collagen-derived angiogenesis inhibitor, suppresses invasion of squamous cell carcinoma. PLoS One 7: e51044.

40. Kamphaus GD, Colorado PC, Panka DJ, Hopfer H, Ramchandran R, et al. (2000) Canstatin, a novel matrix-derived inhibitor of angiogenesis and tumor growth. J Biol Chem 275: 1209-1215.

41. Panka DJ, Mier JW (2003) Canstatin inhibits Akt activation and induces Fasdependent apoptosis in endothelial cells. J Biol Chem 278: 37632-37636.

42. He GA, Luo JX, Zhang TY, Wang FY, Li RF (2003) Canstatin-N fragment inhibits in vitro endothelial cell proliferation and suppresses in vivo tumor growth. Biochem Biophys Res Commun 312: 801-805

43. He GA, Luo JX, Zhang TY, Hu ZS, Wang FY (2004) The C-terminal domain of canstatin suppresses in vivo tumor growth associated with proliferation of endothelial cells. Biochem Biophys Res Commun 318: 354-360.

44. Hwang-Bo J, Yoo KH, Park JH, Jeong HS, Chung IS (2012) Recombinan canstatin inhibits angiopoietin-1-induced angiogenesis and lymphangiogenesis. Int J Cancer 131: 298-309.

45. Magnon C, Galaup A, Mullan B, Rouffiac V, Bouquet C, et al. (2005) Canstatin acts on endothelial and tumor cells via mitochondrial damage initiated through interaction with alphavbeta3 and alphavbeta5 integrins. Cancer Res 65: 4353 4361.

46. Sudhakar A, Boosani CS (2007) Signaling mechanisms of endogenous angiogenesis inhibitors derived from type IV collagen. Gene Regul Syst Bio 1: 217-226.

47. Maeshima Y, Colorado PC, Torre A, Holthaus KA, Grunkemeyer JA, et al. (2000) Distinct antitumor properties of a type IV collagen domain derived from basement membrane. J Biol Chem 275: 21340-21348.

48. Maeshima Y, Sudhakar A, Lively JC, Ueki K, Kharbanda S, et al. (2002) Tumstatin, an endothelial cell-specific inhibitor of protein synthesis. Science 295: $140-143$

49. Han J, Ohno N, Pasco S, Monboisse JC, Borel JP, et al. (1997) A cell binding domain from the alpha3 chain of type IV collagen inhibits proliferation of melanoma cells. J Biol Chem 272: 20395-20401.

50. Pasco S, Han J, Gillery P, Bellon G, Maquart FX, et al. (2000) A specific sequence of the noncollagenous domain of the alpha3(IV) chain of type IV collagen inhibits expression and activation of matrix metalloproteinases by tumor cells. Cancer Res 60: 467-473.

51. Pasco S, Ramont L, Venteo L, Pluot M, Maquart FX, et al. (2004) In vivo overexpression of tumstatin domains by tumor cells inhibits their invasive properties in a mouse melanoma model. Exp Cell Res 301: 251-265.

52. Pasco S, Monboisse JC, Kieffer N (2000) The alpha 3(IV)185-206 peptide from noncollagenous domain 1 of type IV collagen interacts with a novel binding site on the beta 3 subunit of integrin alpha Vbeta 3 and stimulates focal adhesion kinase and phosphatidylinositol 3-kinase phosphorylation. J Biol Chem 275 : 32999-33007.

53. Hamano Y, Zeisberg M, Sugimoto H, Lively JC, Maeshima Y, et al. (2003) Physiological levels of tumstatin, a fragment of collagen IV alpha3 chain, are generated by MMP-9 proteolysis and suppress angiogenesis via alphaV beta3 integrin. Cancer Cell 3: 589-601.

54. Thevenard J, Ramont L, Mir LM, Dupont-Deshorgue A, Maquart FX, et al. (2013) A new anti-tumor strategy based on in vivo tumstatin overexpression after plasmid electrotransfer in muscle. Biochem Biophys Res Commun 432 549-552.

55. Luo YQ, Li-JuanYao, Zhao L, Sun AY, Dong H, et al. (2010) Development of an ELISA for quantification of tumstatin in serum samples and tissue extracts of patients with lung carcinoma. Clin Chim Acta 411: 510-515.

56. Petitclerc E, Boutaud A, Prestayko A, Xu J, Sado Y, et al. (2000) New function for non-collagenous domains of human collagen type IV. Novel integrin ligands inhibiting angiogenesis and tumor growth in vivo. J Biol Chem 275: 8051-8061.

57. Brassart-Pasco S, Sénéchal K, Thevenard J, Ramont L, Devy J, et al. (2012) Tetrastatin, the NC1 domain of the a4(IV) collagen chain: a novel potent antitumor matrikine. PLoS One 7: e29587.

58. Karagiannis ED, Popel AS (2007) Identification of novel short peptides derived from the alpha 4 , alpha 5 , and alpha 6 fibrils of type IV collagen with antiangiogenic properties. Biochem Biophys Res Commun 354: 434-439.

59. Koskimaki JE, Karagiannis ED, Tang BC, Hammers $\mathrm{H}$, Watkins DN, et al (2010) Pentastatin-1, a collagen IV derived 20-mer peptide, suppresses tumor growth in a small cell lung cancer xenograft model. BMC Cancer 10: 29

60. Mundel TM, Yliniemi AM, Maeshima Y, Sugimoto H, Kieran M, et al. (2008) Type IV collagen alpha6 chain-derived noncollagenous domain 1 (alpha6(IV) NC1) inhibits angiogenesis and tumor growth. Int J Cancer 122: 1738-1744.

61. Polette M, Thiblet J, Ploton D, Buisson AC, Monboisse JC, et al. (1997) Distribution of a1(IV) and a3(IV) chains of type IV collagen in lung tumours. Pathol 182: 185-191. 
Citation: Monboisse JC, Oudart JB, Brezillon S, Brassart B, Ramont L, et al. (2013) Control of Tumor Progression by Extracellular Matrix Molecule Fragments, the Matrikines. J Carcinogene Mutagene 4: 148. doi:10.4172/2157-2518.1000148

62. Caudroy S, Cucherousset J, Lorenzato M, Zahm JM, Martinella-Catusse C, et al. (2004) Implication of tumstatin in tumor progression of human bronchopulmonary carcinomas. Hum Pathol 35: 1218-1222.

63. Luo YQ, Ming Z, Zhao L, Yao LJ, Dong H, et al. (2012) Decreased tumstatinmRNA is associated with poor outcome in patients with NSCLC. IUBMB Life 64: 423-431.

64. Hiki Y, Iyama K, Tsuruta J, Egami H, Kamio T, et al. (2002) Differential distribution of basement membrane type IV collagen alpha1(IV), alpha2(IV), alpha5(IV) and alpha6(IV) chains in colorectal epithelial tumors. Pathol Int 52: 224-233

65. Ikeda K, lyama K, Ishikawa N, Egami H, Nakao M, et al. (2006) Loss of expression of type IV collagen alpha5 and alpha6 chains in colorectal cance associated with the hypermethylation of their promoter region. Am J Pathol 168: 856-865.

66. Hirashima K, lyama K, Baba Y, Honda Y, Sado Y, et al. (2013) Differential expression of basement membrane type IV collagen $\alpha 2$ and $\alpha 6$ chains as a prognostic factor in patients with extrahepatic bile duct carcinoma. J Surg Oncol 107: 402-407.

67. Nie XC, Wang JP, Zhu W, Xu XY, Xing YN, et al. (2013) COL4A3 expression correlates with pathogenesis, pathologic behaviors, and prognosis of gastric carcinomas. Hum Pathol 44: 77-86.

68. Ramchandran R, Dhanabal M, Volk R, Waterman MJ, Segal M, et al. (1999) Antiangiogenic activity of restin, NC10 domain of human collagen XV: comparison to endostatin. Biochem Biophys Res Commun 255: 735-739.

69. Rehn M, Pihlajaniemi T (1994) Alpha 1(XVIII), a collagen chain with frequent interruptions in the collagenous sequence, a distinct tissue distribution, and homology with type XV collagen. Proc Natl Acad Sci U S A 91: 4234-4238.

70. O'Reilly MS, Boehm T, Shing Y, Fukai N, Vasios G, et al. (1997) Endostatin: an endogenous inhibitor of angiogenesis and tumor growth. Cell 88: 277-285.

71. Folkman J (2006) Antiangiogenesis in cancer therapy--endostatin and its mechanisms of action. Exp Cell Res 312: 594-607.

72. Ricard-Blum S, Ballut L (2011) Matricryptins derived from collagens and proteoglycans. Front Biosci (Landmark Ed) 16: 674-697.

73. Quélard D, Lavergne E, Hendaoui I, Elamaa H, Tiirola U, et al. (2008) A cryptic frizzled module in cell surface collagen 18 inhibits Wnt/beta-catenin signaling. PLoS One 3: e1878.

74. Hendaoui I, Lavergne E, Lee HS, Hong SH, Kim HZ, et al. (2012) Inhibition of $\mathrm{Wnt} / \beta$-catenin signaling by a soluble collagen-derived frizzled domain interacting with Wnt3a and the receptors frizzled 1 and 8. PLoS One 7: e30601.

75. Myers JC, Li D, Bageris A, Abraham V, Dion AS, et al. (1997) Biochemical and immunohistochemical characterization of human type XIX defines a novel class of basement membrane zone collagens. Am J Pathol 151: 1729-1740.

76. Sumiyoshi $H$, Inoguchi $K$, Khaleduzzaman $M$, Ninomiya $Y$, Yoshioka $H$ (1997) Ubiquitous expression of the alpha1(XIX) collagen gene (Col19a1) during mouse embryogenesis becomes restricted to a few tissues in the adult organism. J Biol Chem 272: 17104-17111.

77. Sumiyoshi H, Mor N, Lee SY, Doty S, Henderson S, et al. (2004) Esophagea muscle physiology and morphogenesis require assembly of a collagen XIX-rich basement membrane zone. J Cell Biol 166: 591-600.

78. Su J, Gorse K, Ramirez F, Fox MA (2010) Collagen XIX is expressed by interneurons and contributes to the formation of hippocampal synapses. $J$ Comp Neurol 518: 229-253.

79. Toubal A, Ramont L, Terryn C, Brassart-Pasco S, Patigny D, et al. (2010) The NC1 domain of type XIX collagen inhibits melanoma cell migration. Eur Dermatol 20: 712-718.

80. Ramont L, Brassart-Pasco S, Thevenard J, Deshorgue A, Venteo L, et al. (2007) The NC1 domain of type XIX collagen inhibits in vivo melanoma growth. Mol Cancer Ther 6: 506-514.

81. Amenta PS, Hadad S, Lee MT, Barnard N, Li D, et al. (2003) Loss of types XV and XIX collagen precedes basement membrane invasion in ductal carcinoma of the female breast. J Pathol 199: 298-308.

82. Oudart JB, Brassart-Pasco S, Luczka E, Dupont-Deshorgue A, Bellon G, et al (2013) Analytical methods for measuring collagen XIX in human cell cultures, tissue extracts, and biological fluids. Anal Biochem 437: 111-117.
83. lozzo RV (2005) Basement membrane proteoglycans: from cellar to ceiling. Nat Rev Mol Cell Biol 6: 646-656.

84. lozzo RV, Sanderson RD (2011) Proteoglycans in cancer biology, tumour microenvironment and angiogenesis. J Cell Mol Med 15: 1013-1031.

85. lozzo RV, Schaefer L (2010) Proteoglycans in health and disease: novel regulatory signaling mechanisms evoked by the small leucine-rich proteoglycans. FEBS J 277: 3864-3875.

86. Brézillon S, Pietraszek K, Maquart FX, Wegrowski Y (2013) Lumican effects in the control of tumour progression and their links with metalloproteinases and integrins. FEBS J 280: 2369-2381.

87. Goldoni S, lozzo RV (2008) Tumor microenvironment: Modulation by decorin and related molecules harboring leucine-rich tandem motifs. Int J Cancer 123 2473-2479.

88. Bi XL, Yang W (2013) Biological functions of decorin in cancer. Chin J Cancer 32: $266-269$

89. Bix G, lozzo RV (2005) Matrix revolutions: "tails" of basement-membrane components with angiostatic functions. Trends Cell Biol 15: 52-60.

90. Zeltz C, Brézillon S, Perreau C, Ramont L, Maquart FX, et al. (2009) Lumcorin: a leucine-rich repeat 9-derived peptide from human lumican inhibiting melanoma cell migration. FEBS Lett 583: 3027-3032.

91. Sulochana KN, Fan H, Jois S, Subramanian V, Sun F, et al. (2005) Peptides derived from human decorin leucine-rich repeat 5 inhibit angiogenesis. $J$ Bio Chem 280: 27935-27948.

92. Brown JC, Sasaki T, Göhring W, Yamada Y, Timpl R (1997) The C-terminal domain $V$ of perlecan promotes beta1 integrin-mediated cell adhesion, binds heparin, nidogen and fibulin-2 and can be modified by glycosaminoglycans. Eur J Biochem 250: 39-46.

93. Bix G, lozzo RV (2008) Novel interactions of perlecan: unraveling perlecan's role in angiogenesis. Microsc Res Tech 71: 339-348.

94. Gonzalez EM, Mongiat M, Slater SJ, Baffa R, lozzo RV (2003) A nove interaction between perlecan protein core and progranulin: potential effects on tumor growth. J Biol Chem 278: 38113-38116.

95. Mongiat M, Otto J, Oldershaw R, Ferrer F, Sato JD, et al. (2001) Fibroblast growth factor-binding protein is a novel partner for perlecan protein core. J Biol Chem 276: 10263-10271.

96. Whitelock JM, Melrose J, lozzo RV (2008) Diverse cell signaling events modulated by perlecan. Biochemistry 47: 11174-11183.

97. Chuang CY, Lord MS, Melrose J, Rees MD, Knox SM, et al. (2010) Heparan sulfate-dependent signaling of fibroblast growth factor 18 by chondrocytederived perlecan. Biochemistry 49: 5524-5532.

98. Gonzalez EM, Reed CC, Bix G, Fu J, Zhang Y, et al. (2005) BMP-1/Tolloid-like metalloproteases process endorepellin, the angiostatic $\mathrm{C}$-terminal fragment of perlecan. J Biol Chem 280: 7080-7087.

99. Mongiat M, Sweeney SM, San Antonio JD, Fu J, lozzo RV (2003) Endorepellin a novel inhibitor of angiogenesis derived from the $\mathrm{C}$ terminus of perlecan. $\mathrm{J} \mathrm{Bio}$ Chem 278: 4238-4249.

100.Bix G, lozzo RA, Woodall B, Burrows M, McQuillan A, et al. (2007) Endorepellin, the C-terminal angiostatic module of perlecan, enhances collagen-platele responses via the alpha2beta1-integrin receptor. Blood 109: 3745-3748.

101. Nyström A, Shaik ZP, Gullberg D, Krieg T, Eckes B, et al. (2009) Role of tyrosine phosphatase SHP-1 in the mechanism of endorepellin angiostatic activity. Blood 114: 4897-4906.

102. Vuillermoz B, Khoruzhenko A, D'Onofrio MF, Ramont L, Venteo L, et al. (2004) The small leucine-rich proteoglycan lumican inhibits melanoma progression. Exp Cell Res 296: 294-306.

103. Brézillon S, Venteo L, Ramont L, D’Onofrio MF, Perreau C, et al. (2007) Expression of lumican, a small leucine-rich proteoglycan with antitumour activity, in human malignant melanoma. Clin Exp Dermatol 32: 405-416.

104.Zeltz C, Brézillon S, Käpylä J, Eble JA, Bobichon H, et al. (2010) Lumican inhibits cell migration through $\alpha 2 \beta 1$ integrin. Exp Cell Res 316: 2922-2931.

105. Brezillon S, Zeltz C, Schneider L, Terryn C, Vuillermoz B, et al. (2009) Lumican inhibits B16F1 melanoma cell lung metastasis. J Physiol Pharmacol 60 Suppl 4: $15-22$. 
Citation: Monboisse JC, Oudart JB, Brezillon S, Brassart B, Ramont L, et al. (2013) Control of Tumor Progression by Extracellular Matrix Molecule Fragments, the Matrikines. J Carcinogene Mutagene 4: 148. doi:10.4172/2157-2518.1000148

106. Brézillon S, Radwanska A, Zeltz C, Malkowski A, Ploton D, et al. (2009) Lumican core protein inhibits melanoma cell migration via alterations of focal adhesion complexes. Cancer Lett 283: 92-100.

107. D’Onofrio MF, Brezillon S, Baranek T, Perreau C, Roughley PJ, et al (2008) Identification of beta1 integrin as mediator of melanoma cell adhesion to lumican. Biochem Biophys Res Commun 365: 266-272

108. Radwanska A, Baczynska D, Nowak D, Brézillon S, Popow A, et al. (2008) Lumican affects actin cytoskeletal organization in human melanoma A375 cells. Life Sci 83: 651-660.

109. Albig AR, Roy TG, Becenti DJ, Schiemann WP (2007) Transcriptome analysis of endothelial cell gene expression induced by growth on matrigel matrices: identification and characterization of MAGP-2 and lumican as novel regulators of angiogenesis. Angiogenesis 10: 197-216.

110. Sharma B, Ramus MD, Kirkwood CT, Sperry EE, Chu PH, et al. (2013) Lumican Exhibits Anti-Angiogenic Activity in a Context Specific Manner. Cancer Microenviron.

111. Niewiarowska J, Brézillon S, Sacewicz-Hofman I, Bednarek R, Maquart FX et al. (2011) Lumican inhibits angiogenesis by interfering with $\alpha 2 \beta 1$ receptor activity and downregulating MMP-14 expression. Thromb Res 128: 452-457.

112. Lee S, Bowrin K, Hamad AR, Chakravarti S (2009) Extracellular matrix lumican deposited on the surface of neutrophils promotes migration by binding to beta2 integrin. J Biol Chem 284: 23662-23669.

113. Zeltz C, Brézillon S, Perreau C, Ramont L, Maquart FX, et al. (2009) Lumcorin: a leucine-rich repeat 9-derived peptide from human lumican inhibiting melanoma cell migration. FEBS Lett 583: 3027-3032.

114. Nikitovic D, Katonis P, Tsatsakis A, Karamanos NK, Tzanakakis GN (2008) Lumican, a small leucine-rich proteoglycan. IUBMB Life 60: 818-823.

115. Lu YP, Ishiwata T, Kawahara K, Watanabe M, Naito Z, et al. (2002) Expression of lumican in human colorectal cancer cells. Pathol Int 52: 519-526.

116. Leygue E, Snell L, Dotzlaw H, Troup S, Hiller-Hitchcock T, et al. (2000) Lumican and decorin are differentially expressed in human breast carcinoma. J Pathol 192: 313-320.

117. Troup S, Njue C, Kliewer EV, Parisien M, Roskelley C, et al. (2003) Reduced expression of the small leucine-rich proteoglycans, lumican, and decorin is associated with poor outcome in node-negative invasive breast cancer. Clin Cancer Res 9: 207-214.

118. Goldoni S, Seidler DG, Heath J, Fassan M, Baffa R, et al. (2008) An antimetastatic role for decorin in breast cancer. Am J Pathol 173: 844-855.

119. Goldoni S, Humphries A, Nyström A, Sattar S, Owens RT, et al. (2009) Decorin is a novel antagonistic ligand of the Met receptor. J Cell Biol 185: 743-754.

120. Fan H, Sulochana KN, Chong YS, Ge R (2008) Decorin derived antiangiogenic peptide LRR5 inhibits endothelial cell migration by interfering with VEGFstimulated NO release. Int J Biochem Cell Biol 40: 2120-2128.

121.Zheng XW, Li Y, Tang FA, Ma J, Zheng PY, et al. (2009) In vivo antitumor effect of canstatin gene on human esophageal carcinoma xenografts in nude mice. Ai Zheng 28: 350-355.

122. Goto T, Ishikawa H, Matsumoto K, Nishimura D, Kusaba M, et al. (2008) Tum-1, a tumstatin fragment, gene delivery into hepatocellular carcinoma suppresses tumor growth through inhibiting angiogenesis. Int J Oncol 33: 3340

123. Magnon C, Opolon P, Connault E, Mir LM, Perricaudet M, et al. (2008) Canstatin gene electrotransfer combined with radiotherapy: preclinical trials for cancer treatment. Gene Ther 15: 1436-1445.

124. Chung IS, Son YI, Ko YJ, Baek CH, Cho JK, et al. (2008) Peritumor injections of purified tumstatin delay tumor growth and lymphatic metastasis in an orthotopic oral squamous cell carcinoma model. Oral Oncol 44: 1118-1126.

125.Boosani CS, Mannam AP, Cosgrove D, Silva R, Hodivala-Dilke KM, et al. (2007) Regulation of COX-2 mediated signaling by alpha3 type IV noncollagenous domain in tumor angiogenesis. Blood 110: 1168-1177.

126. Eikesdal HP, Sugimoto H, Birrane G, Maeshima Y, Cooke VG, et al. (2008) Identification of amino acids essential for the antiangiogenic activity of tumstatin and its use in combination antitumor activity. Proc Natl Acad Sci U S A 105: 15040-15045.

127.Zhang GM, Zhang YM, Fu SB, Liu XH, Fu X, et al. (2008) Effects of cloned tumstatin-related and angiogenesis-inhibitory peptides on proliferation and apoptosis of endothelial cells. Chin Med J (Engl) 121: 2324-2330.

128. Li YJ, Sun LC, He Y, Liu XH, Liu M, et al. (2009) The anti-tumor properties of two tumstatin peptide fragments in human gastric carcinoma. Acta Pharmacol Sin 30: 1307-1315.

129. He Y, Jiang Y, Li YJ, Liu XH, Zhang L, et al. (2010) 19-peptide, a fragment of tumstatin, inhibits the growth of poorly differentiated gastric carcinoma cells in vitro and in vivo. J Gastroenterol Hepatol 25: 935-941.

130. Floquet N, Pasco S, Ramont L, Derreumaux P, Laronze JY, et al. (2004) The antitumor properties of the alpha3(IV)-(185-203) peptide from the NC1 domain of type IV collagen (tumstatin) are conformation-dependent. J Biol Chem 279 : 2091-2100.

131.Wang W, Chen P, Li JL, Pei YF, Shuang QC, et al. (2010) The effects of Tumstatin185-191 on lung adenocarcinoma cell lines and the association with protein kinase $\mathrm{B}$ and extracellular regulated protein kinase activation. Zhonghua Jie He He Hu Xi Za Zhi 33: 123-127.

132. Thevenard J, Floquet N, Ramont L, Prost E, Nuzillard JM, et al. (2006) Structural and antitumor properties of the YSNSG cyclopeptide derived from tumstatin. Chem Biol 13: 1307-1315.

133. Thevenard J, Ramont L, Devy J, Brassart B, Dupont-Deshorgue A, et al. (2010) The YSNSG cyclopeptide derived from tumstatin inhibits tumor angiogenesis by down-regulating endothelial cell migration. Int J Cancer 126: 1055-1066.

134. Wang WB, Zhou YL, Heng DF, Miao CH, Cao YL (2008) Combination of tumor necrosis factor-related apoptosis-inducing ligand (TRAIL) and canstatin gene suppression therapy on breast tumor xenograft growth in mice. Breast Cancer Res Treat 110: 283-295

135. Yao B, He QM, Tian L, Xiao F, Jiang Y, et al. (2005) Enhanced antitumor effect of the combination of tumstatin gene therapy and gemcitabine in murine models. Hum Gene Ther 16: 1075-1086.

136. Bix G, Castello R, Burrows M, Zoeller JJ, Weech M, et al. (2006) Endorepellin in vivo: targeting the tumor vasculature and retarding cancer growth and metabolism. J Natl Cancer Inst 98: 1634-1646.

137. Grant DS, Yenisey C, Rose RW, Tootell M, Santra M, et al. (2002) Decorin suppresses tumor cell-mediated angiogenesis. Oncogene 21: 4765-4777.

138. Sofeu Feugaing DD, Götte M, Viola M (2013) More than matrix: the multifaceted role of decorin in cancer. Eur J Cell Biol 92: 1-11.

139. Shintani K, Matsumine A, Kusuzaki K, Morikawa J, Matsubara T, et al (2008) Decorin suppresses lung metastases of murine osteosarcoma. Oncol Rep 19 : 1533-1539.

140.Peyrode C, Weber V, David E, Vidal A, Auzeloux P, et al. (2012) Quaternary ammonium-melphalan conjugate for anticancer therapy of chondrosarcoma: in vitro and in vivo preclinical studies. Invest New Drugs 30: 1782-1790.

141.Zhou JF, Bai CM, Wang YZ, Li XY, Cheng YJ, et al. (2011) Endostar combined with chemotherapy for treatment of metastatic colorectal and gastric cancer: a pilot study. Chin Med J (Engl) 124: 4299-4303. 